\title{
METALLURGICAL AND SURFACE DAMAGE ANALYSIS IN A COPPER MOLD AFTER SERVICE
}

J. Srnec Novak ${ }^{1}$, A. Lanzutti ${ }^{1}$, D. Benasciutti ${ }^{2}$, S. Carretti ${ }^{3}$, F. De Bona ${ }^{1}$, A. De Luca ${ }^{3}$, L. Moro ${ }^{1}$

University of Udine, Politechnic Department of Engineering and Architecture (DPIA), Via delle Scienze 208, 33100, Udine, Italy. mails: jelena.srnec@uniud.it, alex.lanzutti@uniud.it, francesco.debona@uniud.it, luciano.moro@uni $\underline{\text { ud.it }}$

2 University of Ferrara, Department of Engineering, Via Saragat 1, 44122, Ferrara, Italy. Email:bnsdns@unife.it

3 Danieli Research Center, Via Nazionale 41, 33042, Buttrio (UD), Italy. Emails: s.carretti@danieli.it, a.deluca@danieli.it

\section{Introduction}

Copper mold is the main component of the continuous casting process. The mold is a tube, where a huge thermal flux is transferred from the molten steel, close to the inner surface, to the water cooled outer side. Thus a high thermal gradient takes place across mold walls, generating thermal fatigue cracks in the meniscus area, which is the most thermally stressed region.

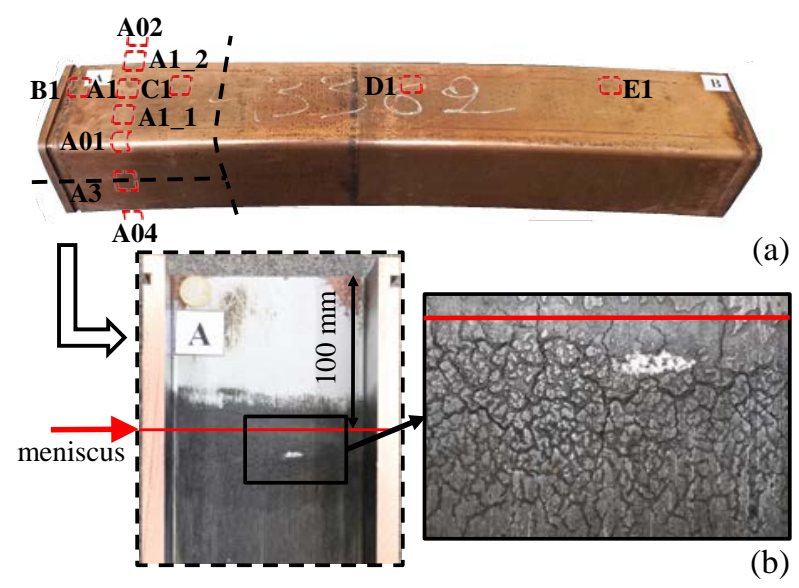

Fig. 1. Mold under investigation with positions of specimens (a), damaged inner surface area (b).

This paper presents a failure analysis of a square copper mold after service; see Fig. 1a. Metallurgical investigations (light microscope and SEM) have been performed on samples extracted from different areas of interest to characterize the mold microstructure and to determine the mechanism of cracking.

\section{Experimental procedure}

The copper mold, removed from service at the end of its service life, has been visual inspected to determine the most damaged areas, as done in [1, 2]. The inner surface of the mold after service is presented in Fig. 1b. A slice of the copper mold has then been extracted in the meniscus area, (region labeled with A in Fig. 1a). In this area 10 metallographic samples have been extracted. Four samples have also been taken from "undamaged" areas (labels B, C, D, E). Each sample underwent to metallographic preparation (grinding and polishing) to obtain a mirror-like surface. The samples have been etched, using a solution of $\mathrm{H}_{2} \mathrm{O}: \mathrm{NH}_{3}: \mathrm{H}_{2} \mathrm{O}_{2}=1: 1: 1$, and then analyzed by light microscope to determine the crack morphology, grain size (intercept method) and the microstructure. Some samples underwent to SEM+EDXS analysis to investigate the origin of deposits inside the cracks.

\section{Results}

The visual inspection has evidenced that the mold is heavily damaged in the meniscus area, as indicated in Fig. 1b. Close examination of the mold inner surface shows that a web of cracks is formed approximately $130 \mathrm{~mm}$ from the mold top, i.e. in the level where the surface of the mold reaches the maximum temperature.

The microstructural examination of the samples, extracted in the area of meniscus, has evidenced the presence of many cracks, mainly in the samples A1, A1_1, A1_2, A3, and A4. These samples are situated in the most stressed region of the mold. Fig. 2a and 2b (samples A3 and A1_2 


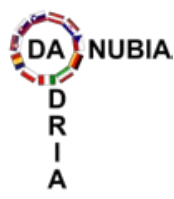

34th Danubia-Adria Symposium on Advances in Experimental Mechanics

University of Trieste, Italy, 2017 respectively) show that cracks initiate at the surface and then propagate through the mold walls. The cracks seem to be transgranular and are contoured of some blue deposits, which will be further investigated by means of SEM+EDXS. It is observed that the crack nucleation region lacks the original chromium protective coating that probably has been detached by the degradation process.

(a)

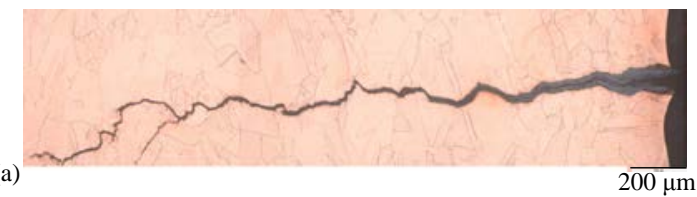

(b)

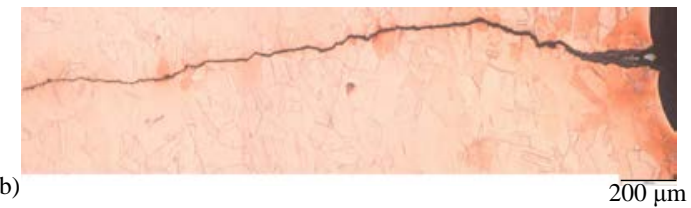

Fig. 2. Cracks on specimen A3 (a), and A1_2 (b).

The microstructure of the material is composed by austenitic equiaxed grains typical of pure $\mathrm{Cu}$. The grain size of the $\mathrm{Cu}$ is coarse and in the range of $\sim 70 \pm 30 \mu \mathrm{m}$. These dimensions are in the range of the microstructural requirements for this kind of application. At surface the material seems to be recrystallized because of the presence of finer grains compared to the bulk of material. The recrystallization process could be produced by the presence of both a strain hardened layer, caused by the machining process of the internal wall of the mold, and of high temperatures, at which the material has been exposed.

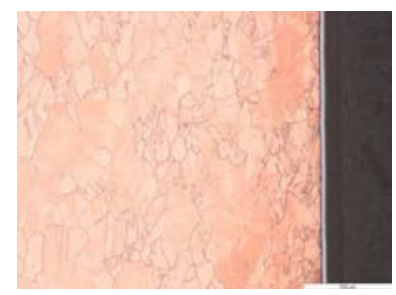

A01, 50 $20 \mu \mathrm{m}$

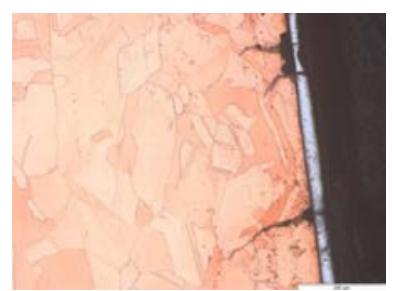

A04, 56 $\pm 24 \mu \mathrm{m}$
Fig. 3. Microstructure of samples taken at corners.
B1, 94 $\pm 23 \mu \mathrm{m}$

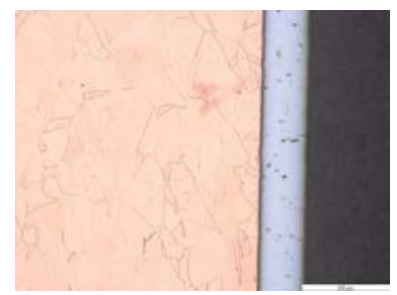

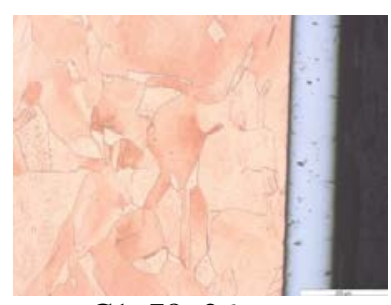

$\mathrm{C} 1,78 \pm 26 \mu \mathrm{m}$
Fig. 4. Microstructure of $\mathrm{B} 1$ and $\mathrm{C} 1$ samples.

Considering samples from corners, only few small cracks are found on one side (e.g. A04), while no visible cracks are observed on the opposite side (e.g. A01), see Fig. 3. Some samples present a detachment of the coating, caused by the wear of the mold. The samples B1 and C1 do not have both visible cracks and the chromium coating layer, which presents a thickness of approximately 100 $\mu \mathrm{m}$ (Fig. 4). Indeed, these samples have been extracted outside the meniscus area, where probably the thermal stresses are lower. The SEM analyses performed on specimen A1, have evidenced the presence of $\mathrm{Pb}, \mathrm{Zn}$ and S, see Fig. 5. These elements probably are present in the molten steel as residuals and they have been infiltrated because of the high chemical affinity with $\mathrm{Cu}$. It is possible that these elements, reacting with the $\mathrm{Cu}$, have produced a brittle phase, which has promoted the crack nucleation and propagation.

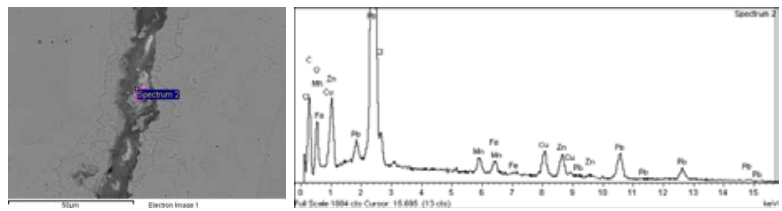

Fig. 5. X-ray spectrum of the damaged zone.

Metallurgical analysis proved the transgranular characteristics of the cracks, thus suggesting that thermal fatigue is the main cause of failure, as suggested in [2].

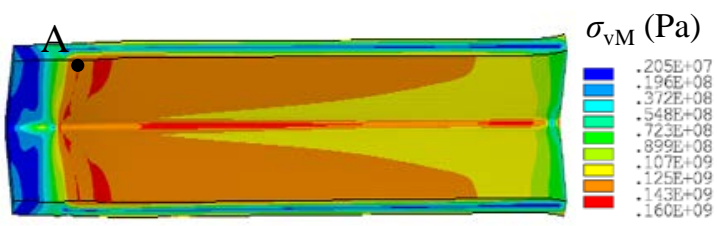

Fig. 6. Von Mises stress distribution.

This hypothesis was also confirmed by results of finite element analyses (see Fig. 6), simulating the cyclic behavior of the mold, which showed critical values of stress and strain in the area where cracks appear [3].

\section{References}

[1] Barella, S. et al., Investigation of failure and damage on a continuous casting copper mould, Eng. Fail. Anal., 36, 2014. pp. 432438.

[2] Park, J.K. et al., Thermal and mechanical behavior of copper molds during thin-slab casting (ii): mold crack formation, Metall. Mater. Trans., 33B, 2002. pp. 437-449.

[3] Novak Srnec, J. et al., Thermo-mechanical finite element simulation and fatigue life 


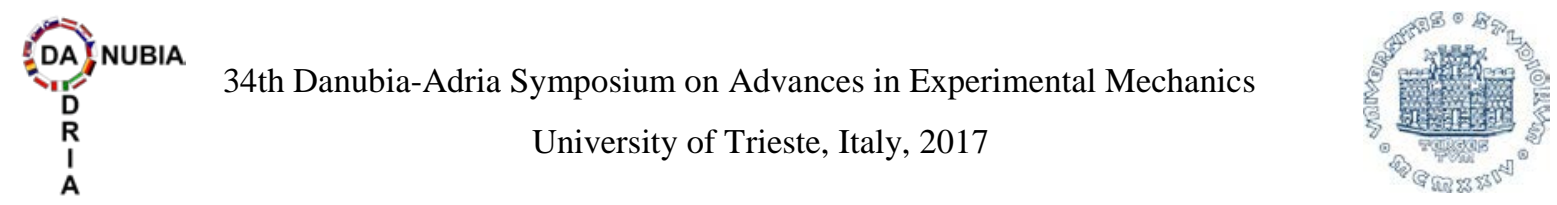

assessment of a copper mould for continuous casting of steel, Procedia Engineering, 133, 2015. pp. 688-697. 